\title{
Oxygen Transport Ceramic Membranes
}

\author{
Quarterly Report
}

July 2006 - September 2006

Principal Authors:

Prof. S. Bandopadhyay

Dr. T. Nithyanantham

Issued: October 2006

DOE Award \# DE-FC26-99FT40054

\author{
University of Alaska Fairbanks \\ Fairbanks, AK 99775
}

\section{Contributing Authors:}

1. Y-W. Sin and H. U. Anderson, Materials Research Center, University of Missouri-Rolla, Rolla, MO 65401

2. Prof. Alan Jacobson and Prof. C.A. Mims; University of Houston/University of Toronto 


\section{DISCLAIMER}

This report was prepared as an account of the work sponsored by an agency of the United States Government. Neither the United States Government nor any agency thereof, nor any of their employees, makes any warranty, express or implied, or assumes any legal liability or responsibility for the accuracy, completeness, or usefulness of any information, apparatus, product, or process disclosed, or represents that its use would not infringe privately owned rights. Reference herein to any specific commercial product, process, or service by trade name, trademark, manufacturer, or otherwise does not necessarily constitute or imply its endorsement, recommendation, or favoring by the United States Government or any agency thereof. The views and opinions of authors expressed herein do not necessarily state or reflect those of the United States Government or any agency thereof. 


\begin{abstract}
The total electrical conductivity and Seebeck coefficient were measured in air on both porous and dense LSFT samples, which were prepared using nano-crystalline powders. The conductivity in air at $900^{\circ} \mathrm{C}$ was about 0.19 and $1.5 \mathrm{~S} / \mathrm{cm}$ for porous and dense LSFT, respectively. The activation energy of conduction for the porous and dense LSFT was about $0.2 \mathrm{eV}$ and $0.20-0.33 \mathrm{eV}$, respectively. The average value of the acceptor dopant concentration based on Seebeck and electrical conductivity measurements on the porous LSFT was calculated to be 0.35 , which suggests that the dopants were fully ionized at the lowest temperature, $400^{\circ} \mathrm{C}$.
\end{abstract}

Thermal analysis of the fractured dual phase membranes at $1000^{\circ} \mathrm{C}$ in air and $\mathrm{N}_{2}$ atmosphere has been carried out and the results were compared with that of the as received dual phase membranes carried out in air and $\mathrm{N}_{2}$. The dual phase samples were calcined at 1000 and $1250^{\circ} \mathrm{C}$ in air and annealed at $1000^{\circ} \mathrm{C}$ in air and $\mathrm{N}_{2}$ for TGA. The results confirmed the non-stoichiometry of the membranes at the elevated temperatures. Fractured dual phase membranes at $1000^{\circ} \mathrm{C}$ in $\mathrm{N}_{2}$ and $\mathrm{CO} / \mathrm{CO}_{2}$ environment have annealed at $1000^{\circ} \mathrm{C}$ in air and $\mathrm{N}_{2}$ and their weight gain was estimated. Thermal expansion of the LSFT and dual phase membranes were characterized using dilatometer in air and $\mathrm{N}_{2}$.

We have pursued understanding of oxygen surface activation on perovskite oxides by compositional variations and detailed SIMS analysis. We have pursued ink-jet printing from solutions as a means of producing films of various perovskite oxide compositions on suitable substrates. Preliminary oxygen isotope infusion results on these materials show the expected variation in oxygen uptake on a matrix of printed $\mathrm{La}_{1-\mathrm{x}} \mathrm{Sr}_{\mathrm{x}} \mathrm{Fe} \mathrm{O}_{3-\mathrm{y}}$ bars. Time of flight SIMS has showed substantial variation in the surface composition of various substrates. We are attempting to detect minor variations which will correlate with variable surface activation rates coefficients. 


\section{TABLE OF CONTENTS}

\section{INTRODUCTION}

\section{EXECUTIVE SUMMARY}

Task 1 Preparation and Characterization of Dense Ceramic oxygen 5 Permeable Membranes

Task 2 Determine material mechanical properties under conditions of high 12 temperature and reactive atmosphere

Task 3 Measurement of Surface Activation/Reaction rates in Ion Transport Membranes using Isotope Tracer and Transient Kinetic Techniques

CONCLUSIONS

LISTS OF ACRONYMS AND ABBREVIATIONS

REFERENCES 


\section{LIST OF GRAPHICAL MATERIALS}

Figure 1. XRD profiles of LSFT sintered in air at 1100 and $1300^{\circ} \mathrm{C}$

Figure 2. Temperature dependence of the total conductivity in air

Figure 3. Total conductivity and Seebeck coefficient of LSFT as a function of temperature.

Figure 4. Charge carrier concentration and Seebeck coefficient of LSFT as a function of temperature

Figure 5. Net acceptor dopant concentration and Seebeck coefficient of LSFT as a function of temperature

Figure 6. $\log (\sigma \mathrm{T})$ vs. 1/T of LSFT and corresponding mobility measured in air as a function of temperature

Figure 7. Effect of temperature and environment on flexural strength of the LSFTCGO membranes.

Figure 8. The weight change during annealing of LSFT-CGO measured by TGA

Figure 9. The weight change during annealing of LSFT-CGO calcined at $1000^{\circ} \mathrm{C}$ and $1250^{\circ} \mathrm{C}$ measured by TGA at $1000^{\circ} \mathrm{C}$.

Figure 10 Effect of flexural test atmosphere on the weight change of the LSFT-CGO.

Figure 11. The dilatometer installed at the ceramic membrane lab and the sample holder with a LSFT-CGO membrane is shown in the inset.

Figure 12. Thermal expansion behavior of the LSFT in air and $\mathrm{N}_{2}$ as a function of temperature.

Figure 13. Effect of thermal cycling on the thermal expansion of the LSFT membrane in $\mathrm{N}_{2}$ atmosphere.

Figure 14. Thermal expansion behavior of the LSFT-CGO in air and $\mathrm{N}_{2}$ atmosphere (a); the thermal expansion of the membranes thermal cycled at $1000^{\circ} \mathrm{C}$ in $\mathrm{N}_{2}(\mathrm{~b})$.

Figure 15. ToFSIMS images (positive ions) of printed, dried and calcined patterns of $\mathrm{La}_{1-\mathrm{x}} \mathrm{Sr}_{\mathrm{x}} \mathrm{FeO}_{3-\mathrm{y}}$ on $\mathrm{YSZ}(100)$.

Figure 16. $\quad{ }^{18} \mathrm{O}$ ToFSIMS image of infused patterned sample of $\mathrm{La}_{1-\mathrm{x}} \mathrm{Sr}_{\mathrm{x}} \mathrm{FeO}_{3-\mathrm{y}}$ on YSZ (100). 


\section{INTRODUCTION}

Conversion of natural gas to liquid fuels and chemicals is a major goal for the Nation as it enters the $21{ }^{\text {st }}$ Century. Technically robust and economically viable processes are needed to capture the value of the vast reserves of natural gas on Alaska's North Slope, and wean the Nation from dependence on foreign petroleum sources. Technologies that are emerging to fulfill this need are all based syngas as an intermediate. Syngas (a mixture of hydrogen and carbon monoxide) is a fundamental building block from which chemicals and fuels can be derived. Lower cost syngas translates directly into more cost-competitive fuels and chemicals.

The currently practiced commercial technology for making syngas is either steam methane reforming (SMR) or a two-step process involving cryogenic oxygen separation followed by natural gas partial oxidation (POX). These high-energy, capital-intensive processes do not always produce syngas at a cost that makes its derivatives competitive with current petroleum-based fuels and chemicals.

In the mid 80's BP invented a radically new technology concept that will have a major economic and energy efficiency impact on the conversion of natural gas to liquid fuels, hydrogen, and chemicals. ${ }^{1}$ This technology, called Electropox, integrates oxygen separation with the oxidation and steam reforming of natural gas into a single process to produce syngas with an economic advantage of 30 to 50 percent over conventional technologies. ${ }^{2}$

The Electropox process uses novel and proprietary solid metal oxide ceramic oxygen transport membranes [OTMs], which selectively conduct both oxide ions and electrons through their lattice structure at elevated temperatures. ${ }^{3}$ Under the influence of an oxygen partial pressure gradient, oxygen ions move through the dense, nonporous membrane lattice at high rates with 100 percent selectivity. Transported oxygen reacts with natural gas on the fuel side of the ceramic membrane in the presence of a catalyst to produce syngas.

\footnotetext{
${ }^{1}$ Mazanec, T. J.; Cable, T. L.; Frye, J. G., Jr.; US 4,793,904, 27 Dec 1988, assigned to The Standard Oil Company (now BP America), Mazanec, T. J.; Cable, T. L.; US 4,802,958, 7 Feb 1989, assigned to the Standard Oil Co. (now BP America), Cable, T. L.; Mazanec, T. J.; Frye, J. G., Jr.; European Patent Application 0399833, 24 May 1990, published 28 November 1990.

${ }^{2}$ Bredesen, R.; Sogge, J.; "A Technical and Economic Assessment of Membrane Reactors for Hydrogen and Syngas Production" presented at Seminar on the Ecol. Applic. of Innovative Membrane Technology in the Chemical Industry", Cetraro, Calabria, Italy, 14 May 1996.

${ }^{3}$ Mazanec, T.J., Interface, 1996; Mazanec, T.J., Solid State Ionics, 70/71, 1994 11-19; "Electropox: BP's Novel Oxidation Technology", T.J. Mazanec, pp 212-225, in "The Role of Oxygen in Improving Chemical Processes", M. Fetizon and W.J. Thomas, eds, Royal Society of Chemistry, London, 1993; "Electropox: BP's Novel Oxidation Technology", T.J. Mazanec, pp 85-96, in "The Activation of Dioxygen and Homogeneous Catalytic Oxidation", D.H.R. Barton, A. E. Martell, D.T. Sawyer, eds, Plenum Press, New York, 1993; "Electrocatalytic Cells for Chemical Reaction", T.J. Mazanec, T.L. Cable, J.G. Frye, Jr.; Prep Petrol Div ACS, San Fran, 1992 37, 135-146; T.J. Mazanec, T.L. Cable, J.G. Frye, Jr.; Solid State Ionics, 1992, 53-56, 111-118.
} 
In 1997 BP entered into an OTM Alliance with Praxair, Amoco, Statoil and Sasol to advance the Electropox technology in an industrially sponsored development program. These five companies have been joined by Phillips Petroleum and now are carrying out a multi-year $\$ 40+$ million program to develop and commercialize the technology. The program targets materials, manufacturing and engineering development issues and culminates in the operation of semiworks and demonstration scale prototype units.

The Electropox process represents a truly revolutionary technology for conversion of natural gas to synthesis gas not only because it combines the three separate unit operations of oxygen separation, methane oxidation and methane steam reforming into a single step, but also because it employs a chemically active ceramic material in a fundamentally new way. On numerous fronts the commercialization of Electropox demands solutions to problems that have never before been accomplished. Basic problems in materials and catalysts, membrane fabrication, model development, and reactor engineering all need solutions to achieve commercial success. Six important issues have been selected as needing understanding on a fundamental level at which the applied Alliance program cannot achieve the breadth and depth of understanding needed for rapid advancement. These issues include:

1. Oxygen diffusion kinetics (University of Houston);

2. Phase stability and stress development (University of Missouri - Rolla);

3. Mechanical property evaluation in thermal and chemical stress fields (University of Alaska Fairbanks)

Statement of Work

Task $1 \quad$ Evaluate phase stability and thermal expansion of candidate perovskite membranes and develop techniques to support these materials on porous metal structures.

Task 2 Determine materials mechanical properties under conditions of high temperatures and reactive atmospheres.

Task $3 \quad$ Measure kinetics of oxygen uptake and transport in ceramic membrane materials under commercially relevant conditions using isotope labeling techniques. 


\section{EXECUTIVE SUMMARY}

The total electrical conductivity and Seebeck coefficient were measured in air on both porous $(50 \%)$ and dense ( $>90 \%)$ LSFT samples, which were prepared using nanocrystalline powders. The conductivity in air at $900^{\circ} \mathrm{C}$ was about 0.19 and $1.5 \mathrm{~S} / \mathrm{cm}$ for porous and dense LSFT, respectively. The activation energy of conduction for the porous and dense LSFT was about $0.2 \mathrm{eV}$ and $0.20-0.33 \mathrm{eV}$, respectively. The average value of the acceptor dopant concentration based on Seebeck and electrical conductivity measurements on the porous LSFT was calculated to be 0.35 , which suggests that the dopants were fully ionized at the lowest temperature, $400^{\circ} \mathrm{C}$.

Thermal analysis of the fractured dual phase membranes at $1000^{\circ} \mathrm{C}$ in air and $\mathrm{N}_{2}$ atmosphere has been carried out and the results were compared with that of the as received dual phase membranes carried out in air and $\mathrm{N}_{2}$. The weight gain was observed at the fractured samples are reversible caused by non- stoichiometry by the membrane. The dual phase samples were calcined at 1000 and $1250^{\circ} \mathrm{C}$ in air and annealed at $1000^{\circ} \mathrm{C}$ in air and $\mathrm{N}_{2}$ for TGA. The results showed the temperatures at which the weight gain stabilizes during annealing for TGA and confirmed the non-stoichiometry at the elevated temperatures. Fractured dual phase membranes at $1000^{\circ} \mathrm{C}$ in $\mathrm{N}_{2}$ and $\mathrm{CO} / \mathrm{CO}_{2}$ environment have annealed at $1000^{\circ} \mathrm{C}$ in air and $\mathrm{N}_{2}$ and their weight gain was estimated.

Thermal expansion of the LSFT and dual phase membranes were characterized using dilatometer in air and $\mathrm{N}_{2}$.

A protocol for ink-jet printing of perovskite oxides onto suitable substrates has been pursued. This method provides model materials for the investigation of composition dependence and interface kinetics of interest to the membrane program. It also has relevance to a parallel program in SOFC cathodes. The initial results show variation in oxygen activation rates on composition, though further analysis is needed.

We have continued to investigate the thermodynamic properties (stability and phase-separation behavior) and total conductivity of prototype membrane materials. The data are needed together with the kinetic information to develop a complete model for the membrane transport. We have previously reported characterization, stoichiometry, conductivity, and dilatometry measurements for several perovskite compositions. 
Recent emphasis on dual phase (ionic conductor + mixed conductor) composite materials continues. The initial results, reported during the last period, on the synthesis of gadolinium doped ceria (GDC) for composite (GDC-perovskite) membranes were extended. Sintered materials have been produced and the stability and permeation properties of these materials are in progress. The membrane isotopic transient reactor is being refurbished to study a composite tubular membrane during the next period. 


\section{Task 1: $\quad$ Preparation and Characterization of Dense Ceramic oxygen Permeable Membranes}

Yong-Wook Sin and H. U. Anderson

Materials Research Center, University of Missouri-Rolla, Rolla, MO 65401

\section{Conductivity and Seebeck coefficient of $\mathrm{La}_{0.2} \mathrm{Sr}_{0.8} \mathrm{Fe}_{0.55} \mathrm{Ti}_{0.45} \mathrm{O}_{3-\delta}(\mathrm{LSFT})$ as a function of temperature}

\section{$\underline{\text { Results and Discussion }}$}

The nano-crystalline LSFT powder prepared using the water based solution process described in previous reports was pressed into bars and subjected to the sintering process at 1100 and $1300^{\circ} \mathrm{C}$ in air. The density of the sintered LSFT was about $90 \%$ and $50 \%$ of theoretical density (based on a theoretical density $=5.7 \mathrm{~g} / \mathrm{cm}^{3}$ ) after sintering at $1300^{\circ} \mathrm{C}$ and $1100^{\circ} \mathrm{C}$, respectively. According to the X-ray results reported in a previous report, the perovskite structure was well developed after annealing the powder at temperatures as low as $600^{\circ} \mathrm{C}$ as well on the porous and dense LSFT samples sintered at 1100 and $1300^{\circ} \mathrm{C}$, respectively (Figure 1). It has been reported in the literature that when conventional solid-state reaction was carried out, $1600^{\circ} \mathrm{C}$ of sintering temperature was achieved to obtain complete solid state reaction and good density for LSFT (the value of density was not specified) $\mathbf{1}^{\mathbf{1}}$. Therefore, the nano-crystalline LSFT powder prepared in $\mathrm{UMR}$ can be sintered at $300^{\circ} \mathrm{C}$ lower temperature than conventionally produced powder. 


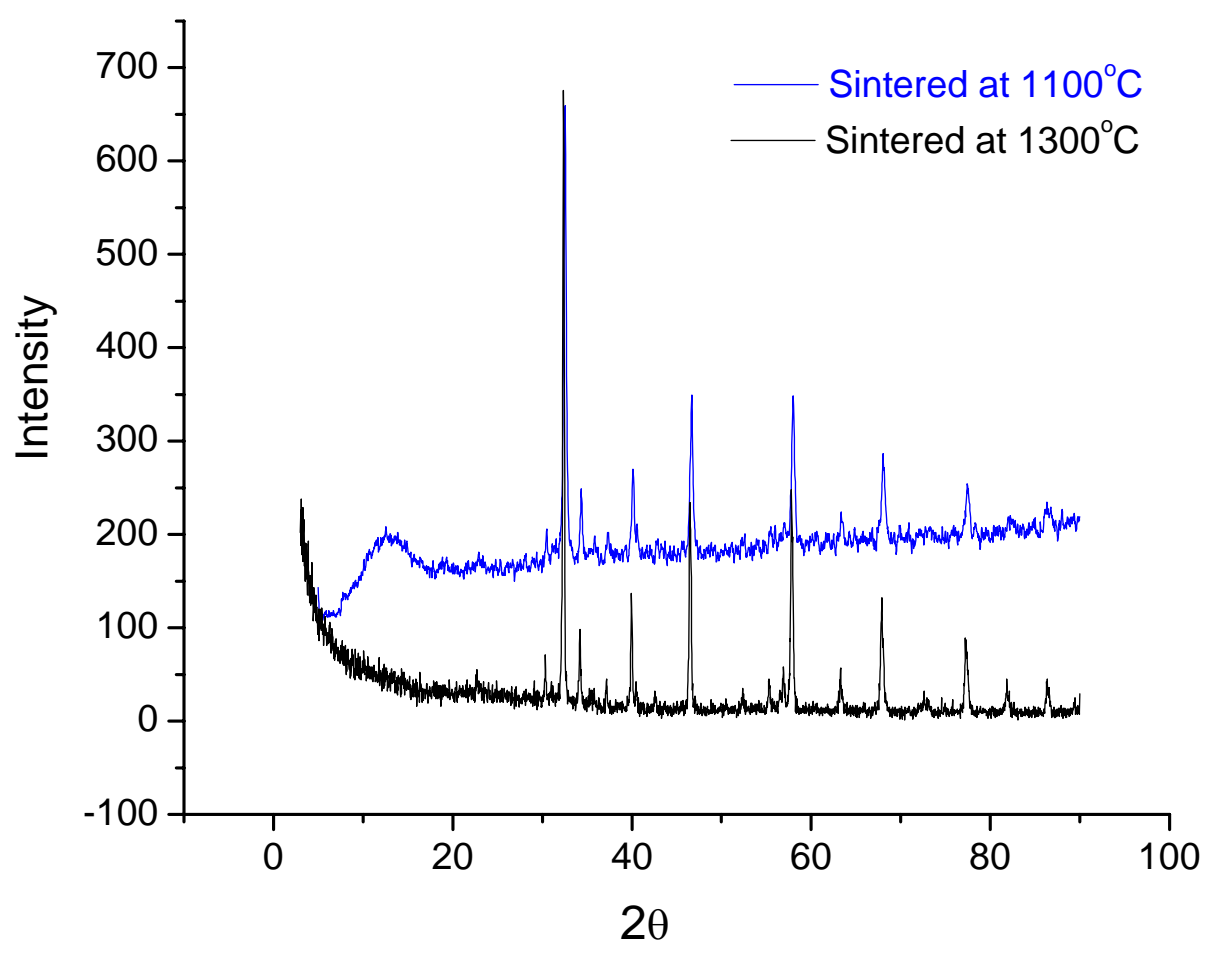

Figure $1 \quad$ XRD profiles of LSFT sintered in air at 1100 and $1300^{\circ} \mathrm{C}$

As has been found true for most perovskite oxides, high density electrical conductivity samples, presents equilibration problems when the ambient conditions are changed. This is certainly true for LSFT, since equilibration times in excess of 72 hours are required for the electrical resistance to stabilize over the entire temperature range employed in the measurement which makes the absolute values obtained at the lower temperatures suspect. As a result, even though the electrical conductivity was about one order of magnitude lower than for dense samples, most of the data were taken on the porous samples since the equilibration time at all temperatures was about 24 hours.

The total conductivity of porous and dense LSFT measured in air as a function of temperature along with data from reference [1] are shown in Figure 2. As can be seen in Figure 2, the temperature dependence of the 90\% dense LSFT and that from reference 
1 are similar with a non-linear behavior with an activation energy which changes from about $0.35 \mathrm{eV}$ below $600{ }^{\circ} \mathrm{C}$ to above $0.2 \mathrm{eV}$ at higher temperatures. The $50 \%$ porosity sample gave very different results in the fact that a linear behavior was observed over the whole temperature range with and activation energy of $0.2 \mathrm{eV}$. This suggests that there were equilibration problems with the dense sample.

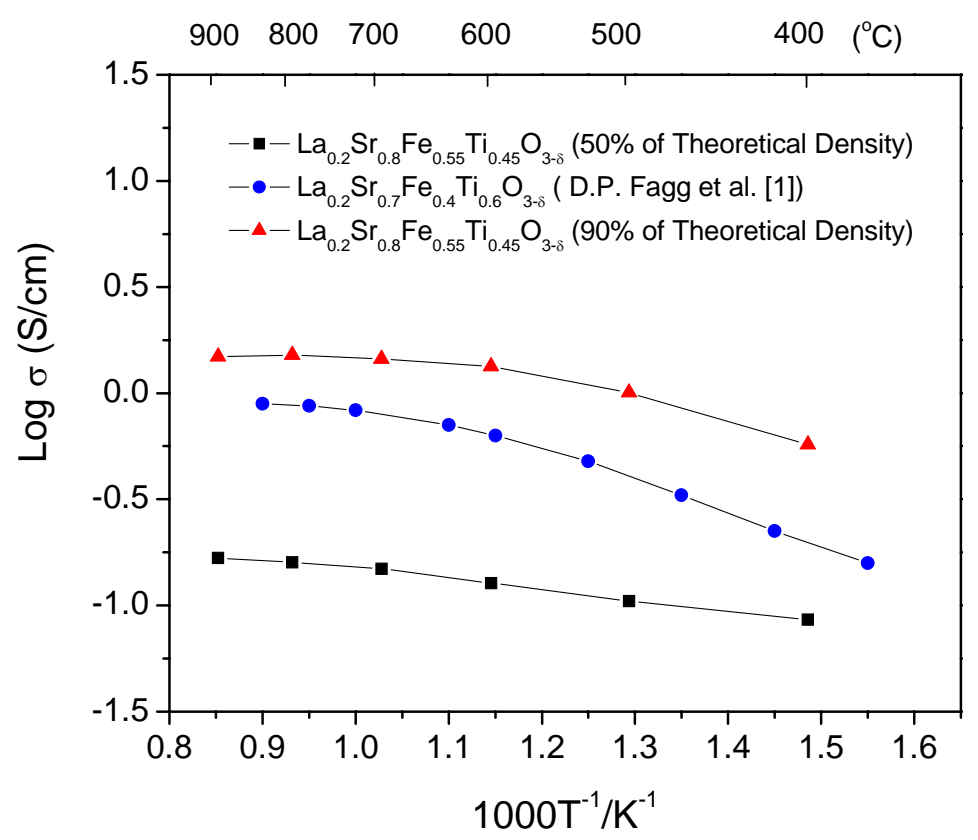

Figure 2 Temperature dependence of the total conductivity in air

Since the porous LSFT was able to be equilibrated over the temperature range used in these measurements, it was used to obtain Seebeck Coefficients, charge carrier concentrations, and mobility. Figure 3 exhibits the total conductivity versus Seebeck 
coefficient in air as a function of temperature up to $900^{\circ} \mathrm{C}$. The Seebeck Coefficient and charge carrier concentration are inversely related (Figure 4) through the relationship

$$
\mathrm{Q}= \pm \frac{\mathrm{k}}{\mathrm{e}}\left[\ln \left(\frac{1-\mathrm{c}}{\mathrm{c}}\right)\right]+\alpha^{*}
$$

where $\mathrm{Q}$ is the Seebeck Coefficient in $\mu \mathrm{V} / \mathrm{K}$ or $\mu \mathrm{V} / \mathrm{C}, \mathrm{k}$ is Boltzmann's constant, $\mathrm{c}$ is the ratio of charge carriers to available conduction sites and $\alpha^{*}$ is a contribution arising from vibrational entropy of transport. In most cases of electronic transport, the magnitude of

$\alpha^{*}$ is rather small and thus is generally negligible. As shown in Figure 5, the average value of the net acceptor dopant concentration as a function of temperature was found to be approximately 0.35. In $\mathrm{La}_{0.2} \mathrm{Sr}_{0.8} \mathrm{Fe}_{0.55} \mathrm{Ti}_{0.45} \mathrm{O}_{3-\delta}$ (LSFT), the acceptor $\left(\left[\mathrm{Sr}_{\mathrm{L}}^{\prime}\right]\right.$ ) is compensated by the donor $\left(\left[\mathrm{Ti}^{\circ} \mathrm{Fe}\right]\right)$, thus if the dopants are distributed in the lattice and are fully ionized, the hole concentration is given by the relation $\mathrm{p}=\left[\mathrm{Sr}_{\mathrm{La}}^{\prime}\right]-\left[\mathrm{Ti}^{\bullet} \mathrm{Fe}\right]$. Thus for the composition used in study, the net hole concentration should be, $p=0.8-0.45$ or 0.35, which agrees with that calculated from the Seebeck measurements (Figure 5). This suggests that both the donors and acceptors were completely ionized at the lowest temperature, $400^{\circ} \mathrm{C}$ and were homogeneously incorporated into the perovskite lattice.

The hole mobility was calculated using the electrical conductivity and carrier concentration data and the results along with the electrical conductivity of the $50 \%$ porosity samples are shown Figure 6. The activation energy for the mobility is $0.2 \mathrm{eV}$ which implies that LSFT conducts via the small polaron conduction mechanism. 


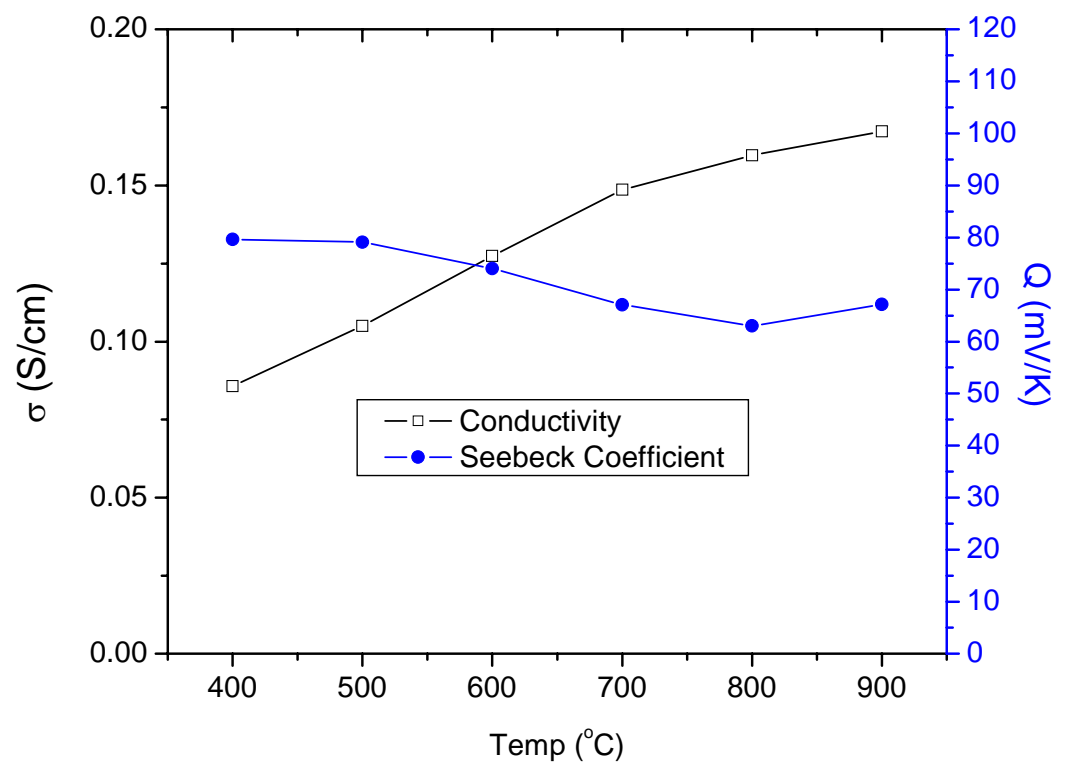

Figure 3 Total conductivity and Seebeck coefficient of LSFT as a function of temperature.

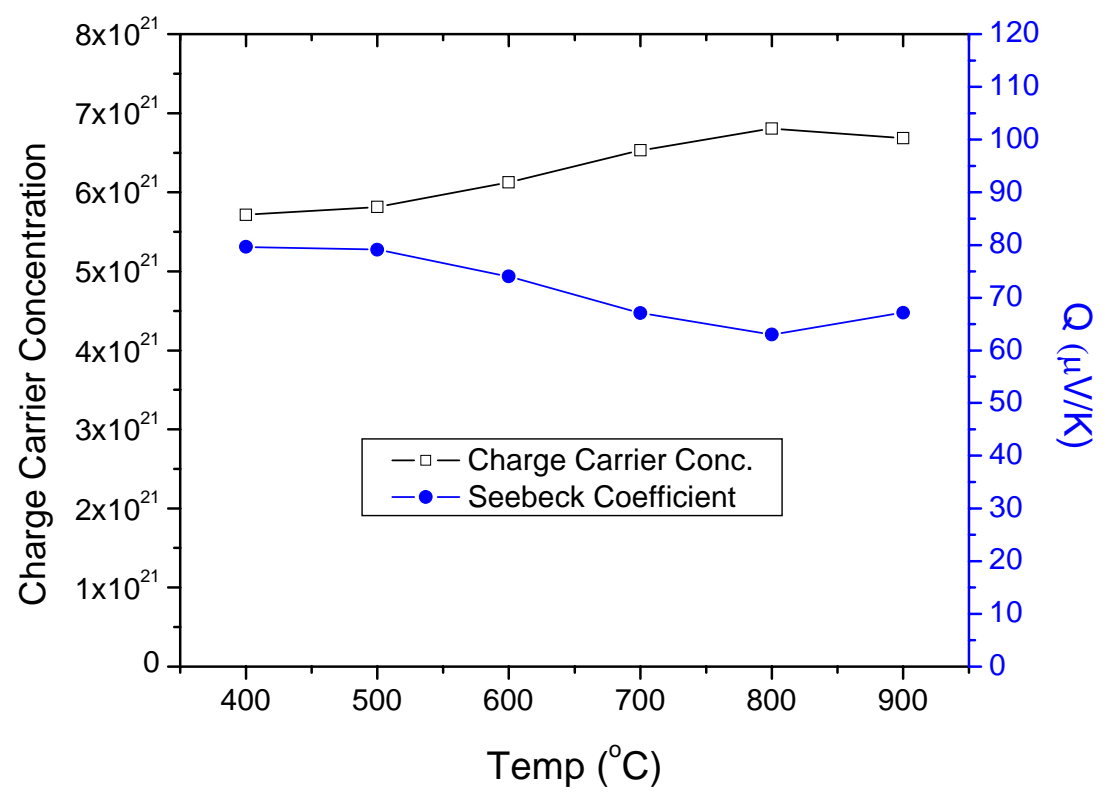

Figure 4 Charge carrier concentration and Seebeck coefficient of LSFT as a function of temperature 


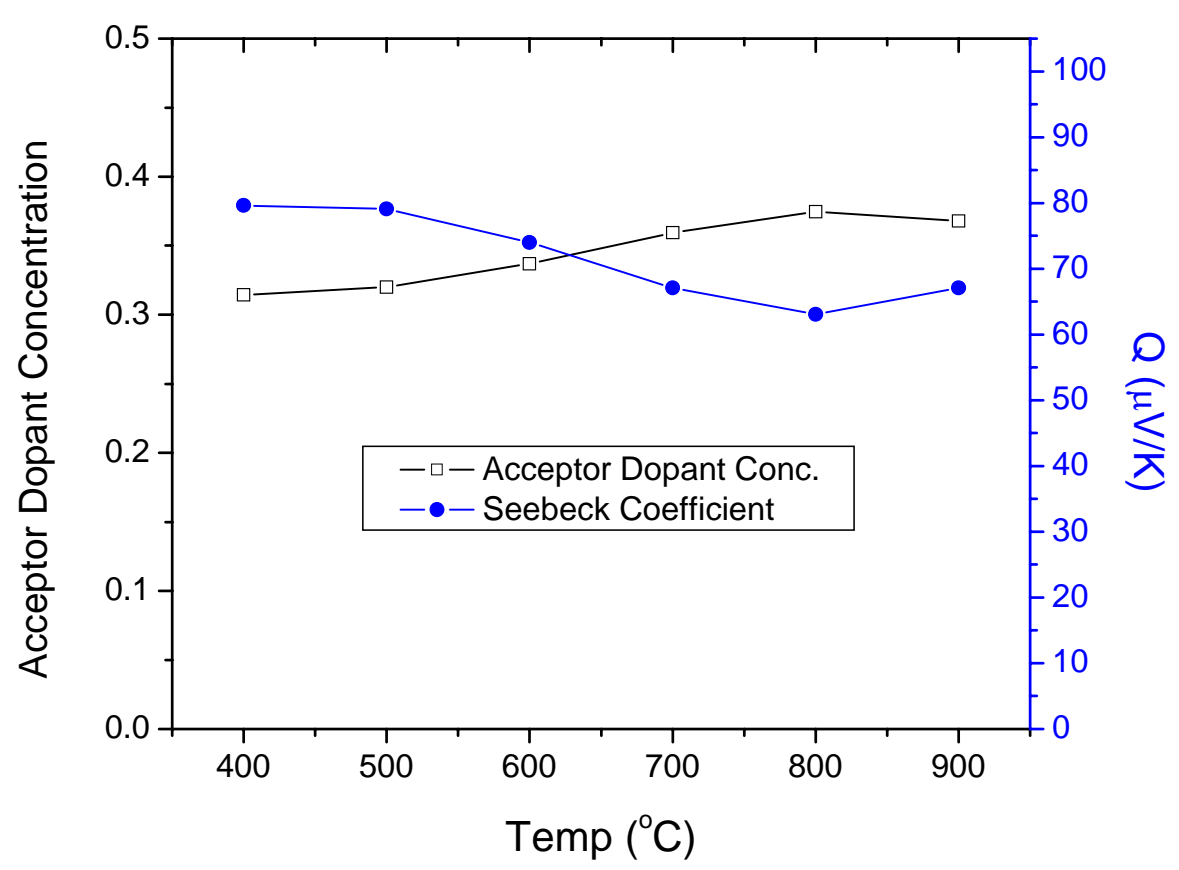

Figure 5 Net acceptor dopant concentration and Seebeck coefficient of LSFT as a function of temperature

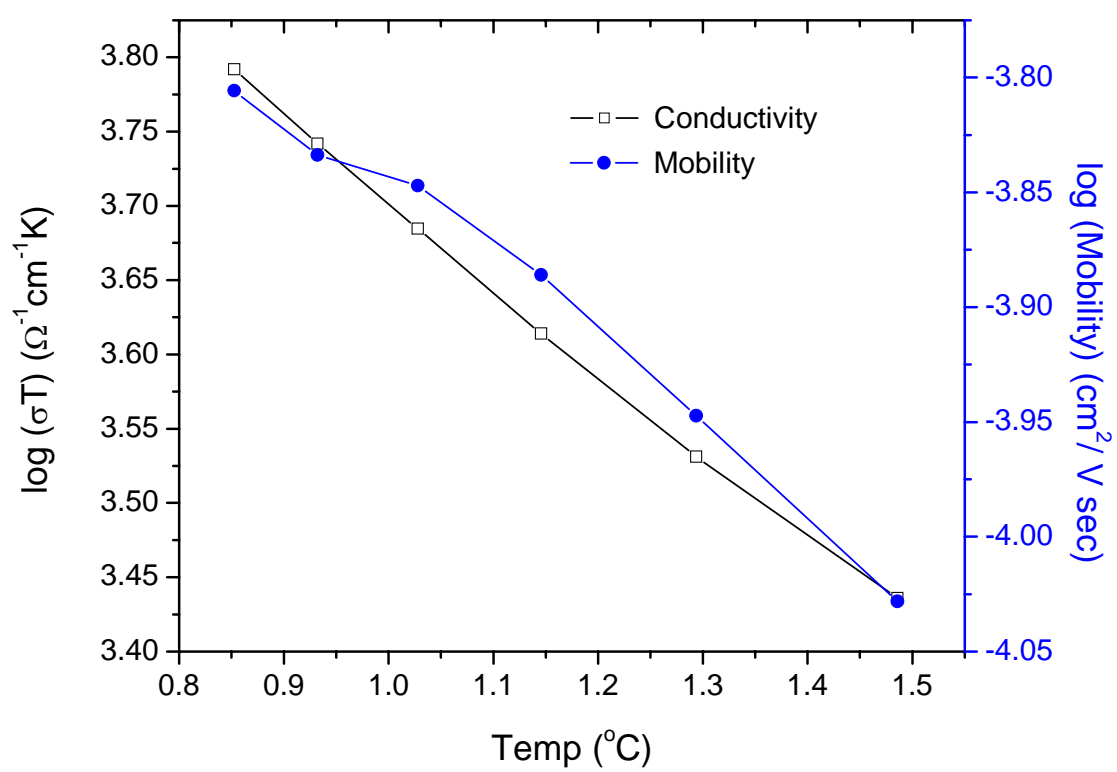

Figure $6 \quad \log (\sigma \mathrm{T})$ vs. 1/T of LSFT and corresponding mobility measured in air as a function of temperature 


\section{Future Work}

1. More investigation of total conductivity and Seebeck Coefficient will be carried out as a function of oxygen activity.

2. The chemical analysis on the LSFT sample will be carried out using XRD and SEM-EDAX after the LSFT is subjected to the low oxygen atmosphere.

3. The relation among the charge carrier concentration, mobility, and net acceptor dopant concentration will be evaluated, which will allow improvements in our understanding to the conduction processes.

\section{Reference}

1. D.P. Fagg et al., Solid State Ionics, 156 (2003) 45-57 


\title{
Task 2: $\quad$ Determine material mechanical properties under conditions of high temperature and reactive atmosphere
}

\author{
Prof. S. Bandopadhyay and Dr. T. Nithyanantham \\ University of Alaska Fairbanks, AK 99775
}

\section{Experimental:}

The flexural strength tests at elevated temperatures in $\mathrm{N}_{2}$ and $\mathrm{CO} / \mathrm{CO}_{2}$ environments were initiated and the effect of strain rate on the strength of dual phase membranes were studied at $1000^{\circ} \mathrm{C}$ in air and $\mathrm{N}_{2}$ atmosphere. In most of the flexural strength experiments that were carried out at high temperatures, the specimen misalignment caused a fracture at one of the ceramic rollers or deformation of the sample caused by the local creep. Hence, it was decided to seek the professional help to machine and polish the flexural strength test specimens in order to achieve the sample dimension specified by ASTM. It is important to study and understand the fracture mechanisms of these materials in the reactive test conditions in order to estimate the material properties at the service conditions. While the strength of the membranes is mostly governed by critical flaws, the crack propagation behavior may be controlled by many other parameters such as the stoichiometry, and the decomposition of the membranes. An understanding of the oxygen deficiency at elevated temperatures using thermal analysis in air and inert atmosphere may shed some light on the stoichiometry of the membranes.

Thermal analysis on the samples was carried out using Perkin Elmer-Pyris Diamond TG/DTA. The $\mathrm{N}_{2}$ was used as purge gas $(200 \mathrm{ml} / \mathrm{min})$ and the analysis were carried out in the air also. Some of the LSFT samples were calcined at 1000 and $1250^{\circ} \mathrm{C}$ prior to the thermal analysis in air and $\mathrm{N}_{2}$ atmosphere and annealed to $1000^{\circ} \mathrm{C}$ for TGA.

New dilatometer (Netzsch DIL 402 PC) was procured and installed to study the thermal expansion of the membranes in the air and inert atmosphere. The test specimens were machined from the rectangular test bars to meet the dilatometer sample preparation 
specifications. The correction run was given for the alumina push rods using sapphire as a standard and the correction was done when the actual test was carried out for membranes.

\section{Results and discussion:}

The flexural strength analysis of the LSFT-CGO in room temperature and at $1000^{\circ} \mathrm{C}$ in $\mathrm{N}_{2}$ atmosphere is shown in figure 7. The strain rate was maintained as $60 \mu \mathrm{m} / \mathrm{min}$ for both the tests and the strength values obtained at the room temperature and at $\mathrm{N}_{2}$ atmosphere are 104.8 MPa and 51.2 MPa respectively.
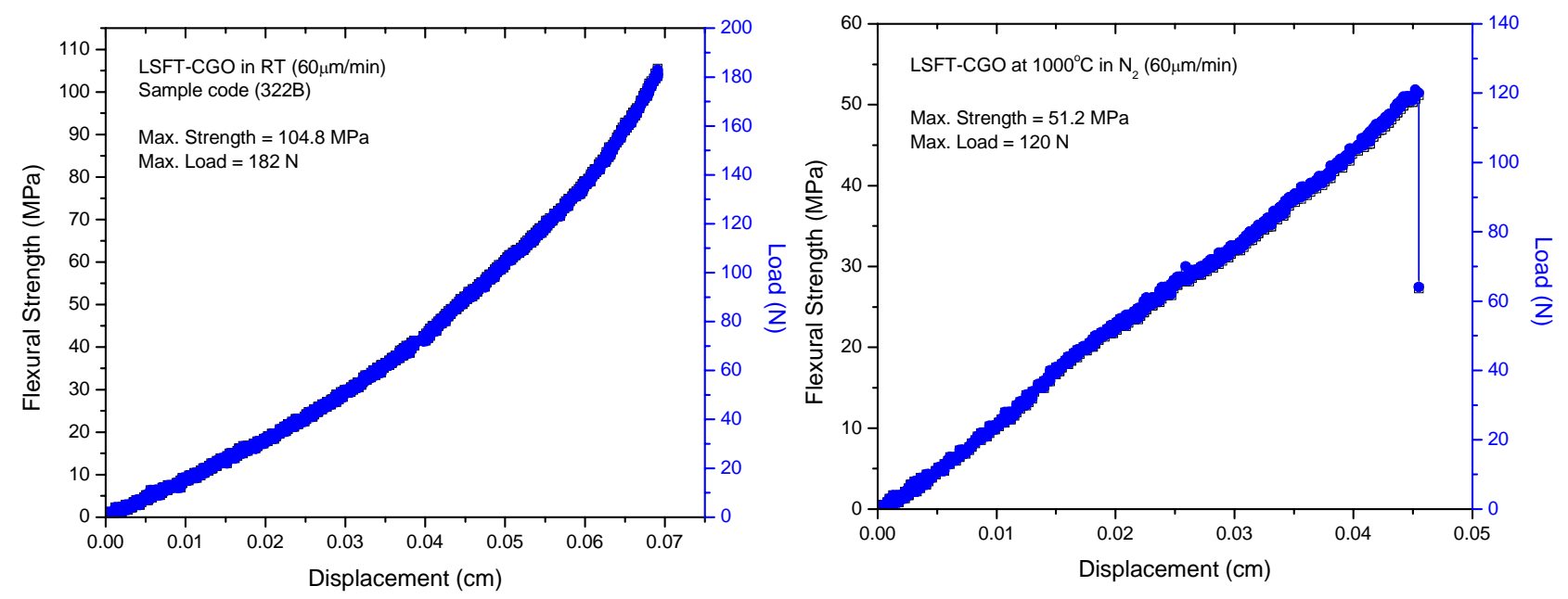

Figure 7. Effect of temperature and environment on flexural strength of the LSFTCGO membranes.

The reduction in the strength can be attributed to the formation of new flaws or enlargement of existing flaws at the high temperature. The perovskite membranes experience the oxygen non-stoichiometry $\delta$ for a doped perovskite type ceramic as a function of temperature and oxygen partial pressure. By changing the temperature or the oxygen partial pressure, the oxygen stoichiometry, or the oxygen content in the solid changes. Within the certain range of temperature and oxygen partial pressure, the change of the oxygen nonstoichiometry does not affect its perovskite structure and the change in the oxygen content is reversible. Hence, studying the effect of high temperature and environment can help to understand the fracture mechanism involved in the process. The LSFT-CGO test specimens fractured at room temperature and $1000^{\circ} \mathrm{C}$ in $\mathrm{N}_{2}$ were 
characterized using TGDTA. The as-received LSFT-CGO was also calcined at $1000^{\circ} \mathrm{C}$ in air and $\mathrm{N}_{2}$ and characterized using thermal analysis. In order to understand the reversible oxygen content, few samples were calcined at $1250^{\circ} \mathrm{C}$ in air prior to the thermal analysis. The results were compared with the results of the as received LSFT-CGO membranes.

The fractured samples were analyzed using TGDTA in air and $\mathrm{N}_{2}$. The change in weight during the exposure of as received LSFT-CGO in $\mathrm{N}_{2}$ and air is shown in Figure 8. The weight loss is reversible in the air and it is, however, irreversible in the $\mathrm{N}_{2}$ atmosphere. The reversible weight loss in air was approx. $0.2 \%$ and the maximum weight loss in the $\mathrm{N}_{2}$ atmosphere is about $0.6 \%$.
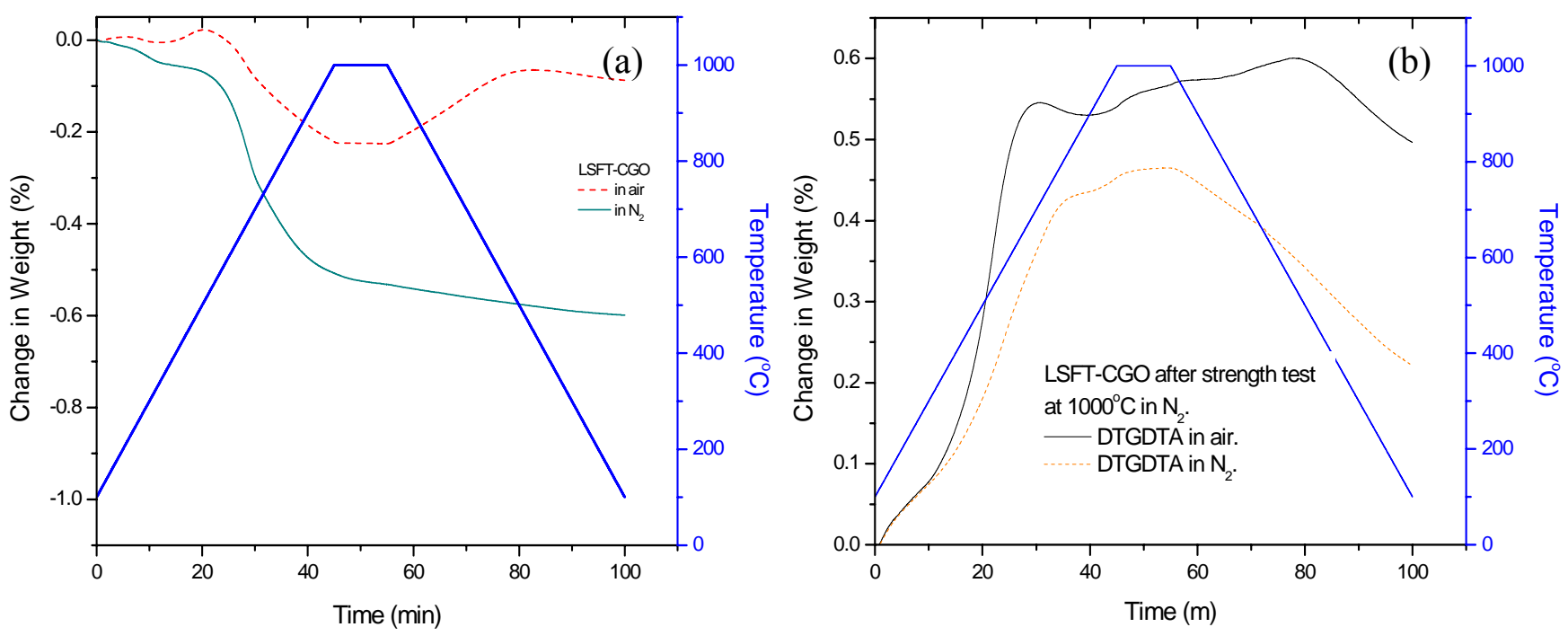

Figure 8. The weight change during annealing of LSFT-CGO measured by TGA

It can be observed from figure 8 that the fractured sample in $\mathrm{N}_{2}$ gains a weight of $0.6 \%$ during annealing as indicated in the thermal analysis. Figure $8(\mathrm{~b})$ shows the weight gain during heating of the membrane and the weight gain almost stabilizes at $500^{\circ} \mathrm{C}$. The weight gain in the $\mathrm{N}_{2}$ rich atmosphere is comparatively less and in both experiments desorption of oxygen is recorded during cooling.

The change in weight during annealing of the LSFT-CGO which was calcined at 1000 and $1250^{\circ} \mathrm{C}$ in air is shown in figure 9. 

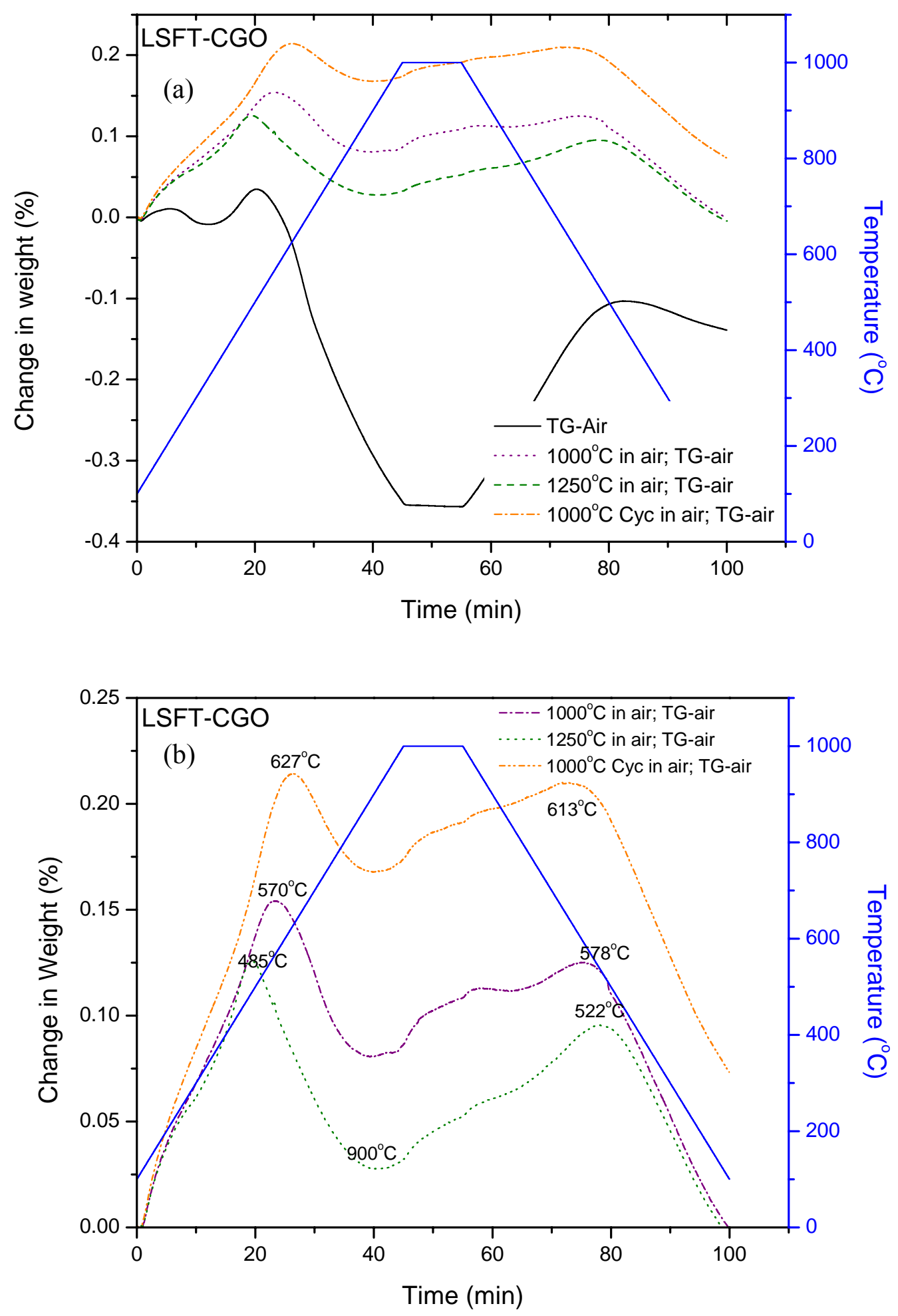

Figure 9. The weight change during annealing of LSFT-CGO calcined at $1000^{\circ} \mathrm{C}$ and $1250^{\circ} \mathrm{C}$ measured by TGA at $1000^{\circ} \mathrm{C}$. 
All the calcined samples gained weight during annealing and they lost weight during cooling. Since the change in weight is reversible, it ensures that the oxygen loss is the reason for the weight change. A thermal cycle was employed on few LSFT -CGO at $1000^{\circ} \mathrm{C}$ in air prior to annealing at $1000^{\circ} \mathrm{C}$ for thermal analysis. The thermal cycled sample gains a weight of $0.2 \%$ and looses the weight during cooling. Figure 9 (b) shows the temperatures at which the weight gain saturates during annealing and the temperatures at which the weight loss is started. For the samples calcined at $1000^{\circ} \mathrm{C}$, the weight changes are marked around $570^{\circ} \mathrm{C}$. As the sample was annealed after the thermal cycling at $1000^{\circ} \mathrm{C}$, the temperatures at which the weight losses are marked have increased. It may be interesting to note that a similar pattern in the TGA curves during annealing for all the samples calcined or thermal cycled at $1000^{\circ} \mathrm{C}$ and $1250^{\circ} \mathrm{C}$ in air. This clearly confirms the LSFT-CGO undergoes a structural change or change in the nonstoichiometry at high temperature. The LSFT-CGO specimens fractured at $1000^{\circ} \mathrm{C}$ in $\mathrm{N}_{2}$ and $\mathrm{CO} / \mathrm{CO}_{2}$ atmosphere were annealed at $1000^{\circ} \mathrm{C}$ for TGA in air and $\mathrm{N}_{2}$ atmosphere and the results are shown in figure 10.

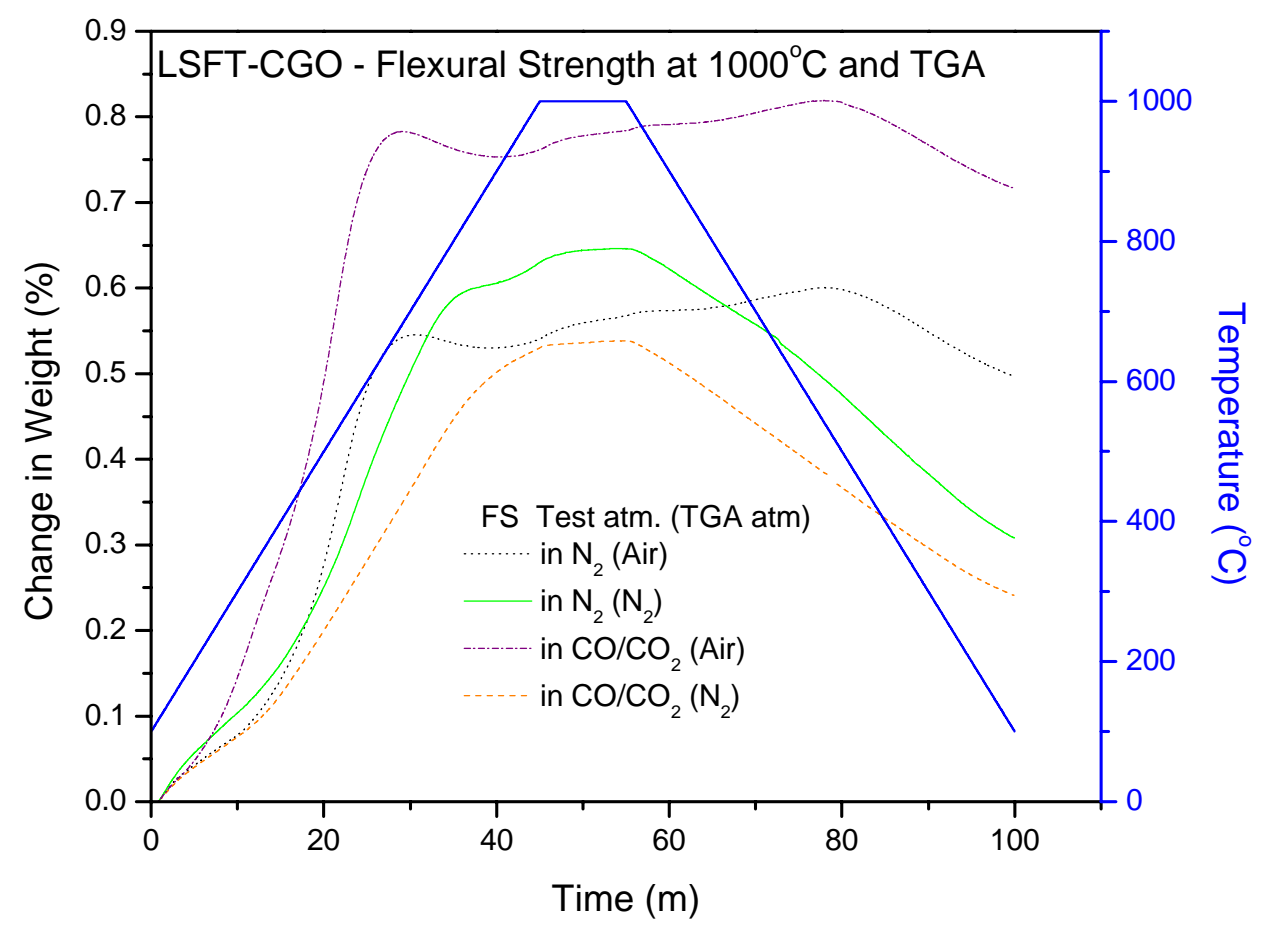

Figure 10. Effect of flexural test atmosphere on the weight change of the LSFT-CGO. 
The LSFT-CGO membranes fractured at the $1000^{\circ} \mathrm{C}$ in $\mathrm{N}_{2}$ gains a weight of 0.5 $\%$ when they are annealed at $1000^{\circ} \mathrm{C}$ during TGA. The same LSFT-CGO membranes gain about $0.6 \%$ of weight when it was annealed at $\mathrm{N}_{2}$, but unlike in the air, the membrane looses the weight during cooling. The membranes fractured at $\mathrm{CO} / \mathrm{CO}_{2}$ environment at $1000^{\circ} \mathrm{C}$ also gains a weight of $0.8 \%$ saturates at the weight even during cooling. This result is quite obvious when the membrane is exposed to an environment in which the partial pressure of oxygen is less at the high temperature.

This study confirms the nonstoichiometry of the oxygen at high temperatures in an inert and reducing atmosphere. X-ray diffraction analysis of the membranes fractured at these test conditions may be able to elucidate the changes associated with the crystal structure of the membranes.

\section{Thermal Expansion studies:}

The thermal expansion of the membranes is very important to material phenomenon to be studied, particularly for materials at high temperatures. In the dual phase membranes the thermal expansion mismatch could be a potential source for nucleating new flaws and reducing the strength of the material. The dilatometer was installed and the correction runs were carried out for the standard (sapphire) rods. Figure 11 shows the photograph of the dilatometer installed at the ceramic membrane lab and the sample holder with the LSFT-CGO membrane (inset). $\mathrm{N}_{2}$ can be used a purge gas and the heating rates can be varied to a desired condition. The thermal expansion can be measured and plotted in the PC using the data accusation system.

The thermal expansion of the LSFT was studied in the air and $\mathrm{N}_{2}$ atmosphere and shown in the figure 12. The thermal expansion is almost similar for the LSFT in the air and $\mathrm{N}_{2}$ atmosphere. Also, thermal expansion of the membranes was not monotonic and the coefficient of thermal expansion changes around $500^{\circ} \mathrm{C}$ in both the environments. It is interesting to note from TGA around this temperatures the membranes experiences a change in the oxygen content. 


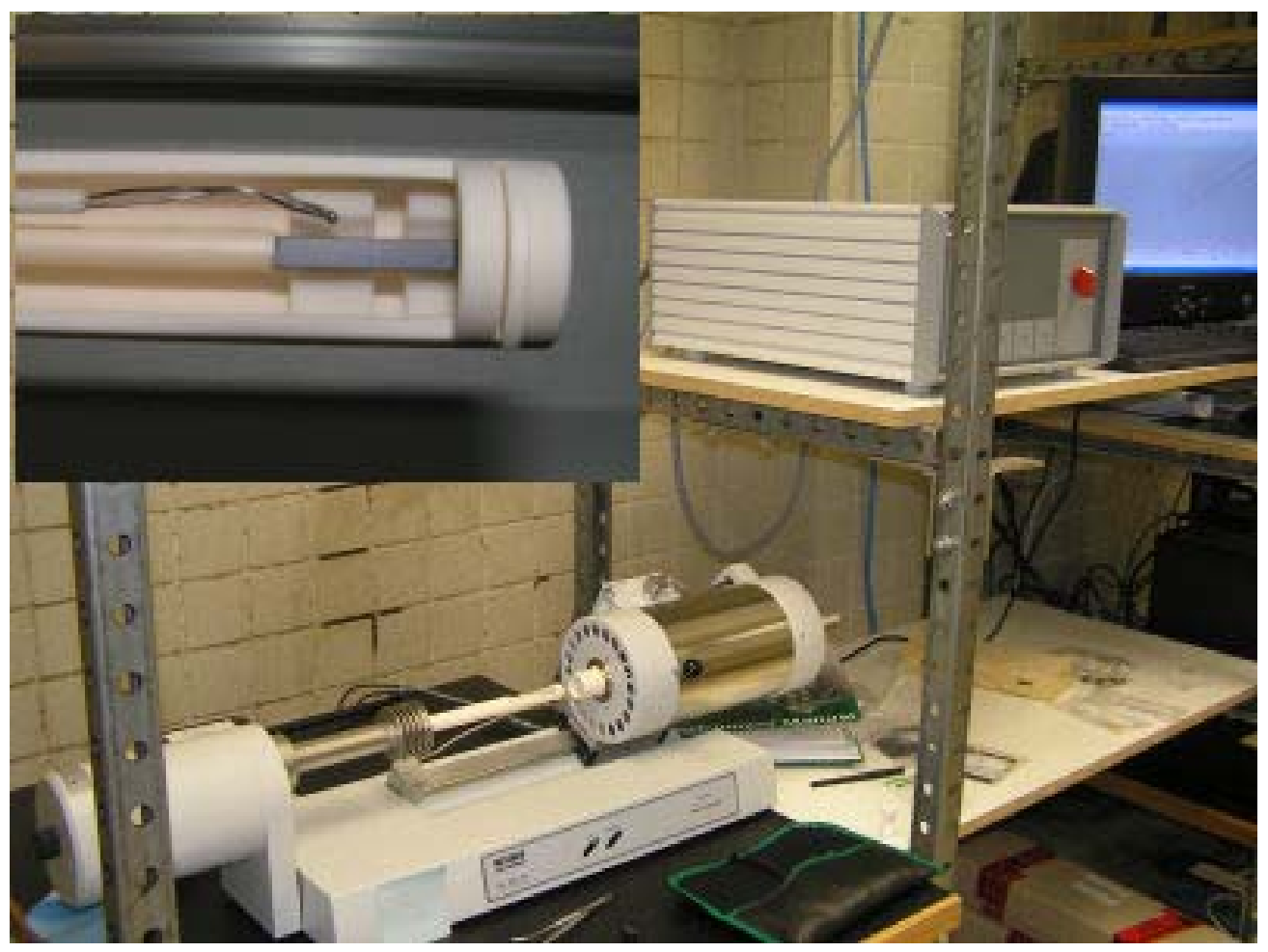

Figure 11. The dilatometer installed at the ceramic membrane lab and the sample holder with a LSFT-CGO membrane is shown in the inset.
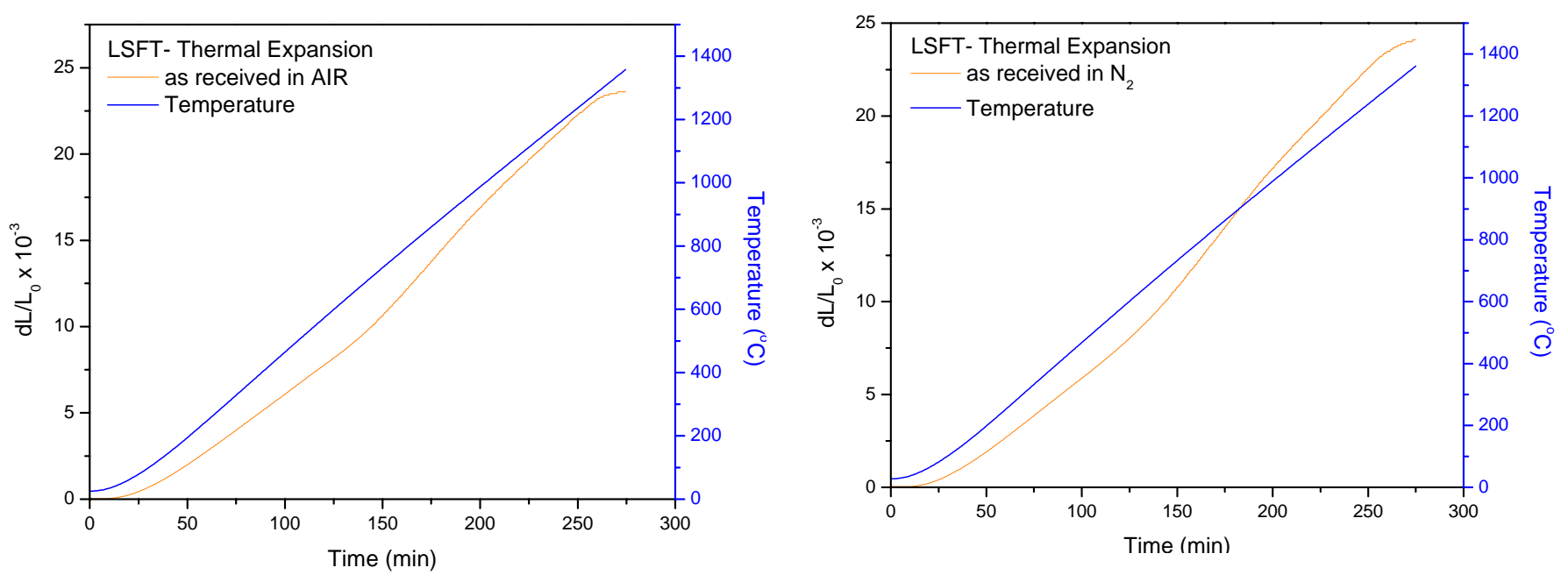

Figure 12. Thermal expansion behavior of the LSFT in air and $\mathrm{N}_{2}$ as a function of temperature. 
At $1400^{\circ} \mathrm{C}$, there was shrinkage that can be observed from the figure 12 in both the environments. This shrinkage might be due to the sintering of the membranes. Thermal expansion of the LSFT was studied in a cyclic mode. The membrane was annealed to $1000^{\circ} \mathrm{C}$ with heating rate of $5 \mathrm{~K} / \mathrm{min}$ and thermal expansion was measured. The same sample was annealed again to $1000^{\circ} \mathrm{C}$ without removing from the sample holder. Figure 13 shows the thermal expansion LSFT during thermal cycling.

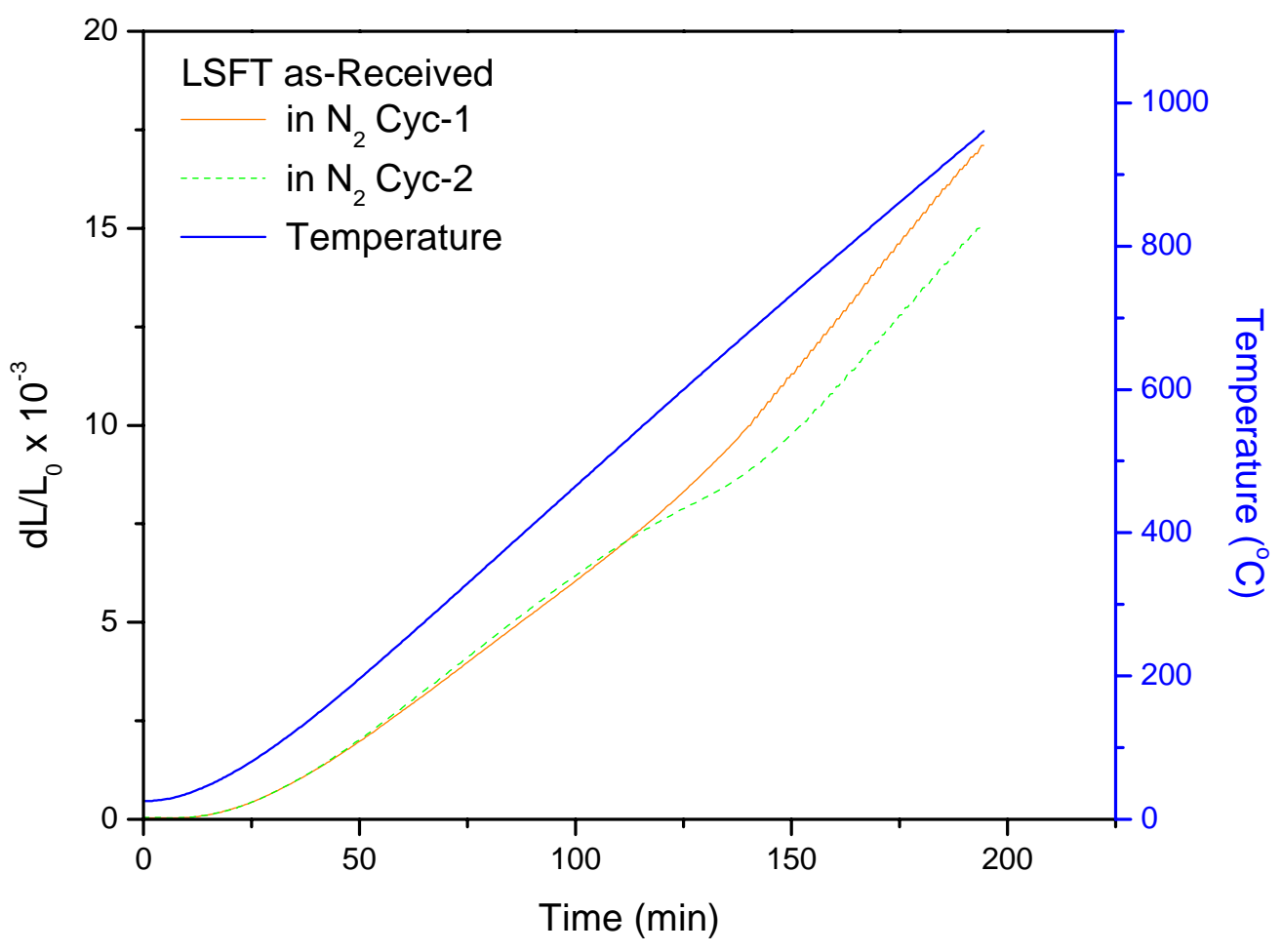

Figure 13. Effect of thermal cycling on the thermal expansion of the LSFT membrane in $\mathrm{N}_{2}$ atmosphere.

There was a significant change in the thermal expansion at $400^{\circ} \mathrm{C}$ during the $2^{\text {nd }}$ cycle. This may be due to the effect of non-stoichiometry in the membrane, which needs to be studied in detail to correlate this result with the TGA. Similar thermal expansion studies were carried out for LSFT-CGO in air and $\mathrm{N}_{2}$ atmosphere. Figure 14 (a) shows the thermal expansion curves for the dual phase membrane. 

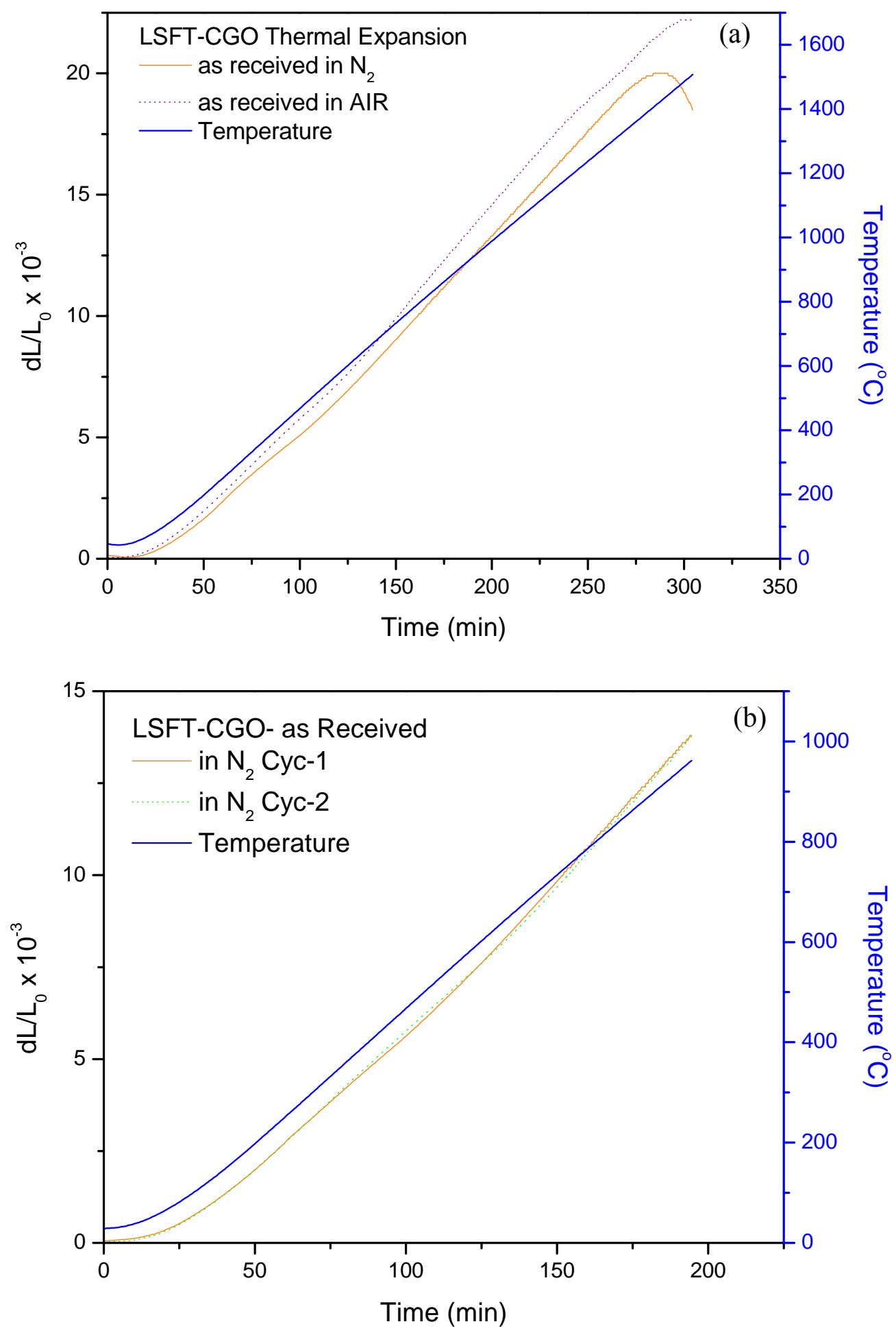

Figure 14. Thermal expansion behavior of the LSFT-CGO in air and $\mathrm{N}_{2}$ atmosphere (a); the thermal expansion of the membranes thermal cycled at $1000^{\circ} \mathrm{C}$ in $\mathrm{N}_{2}(\mathrm{~b})$. 
The thermal expansion was done for the thermal cycled membranes and no significant change was observed with the dual phase membranes. This expansion could be calculated in air and $\mathrm{N}_{2}$ and used to understand the oxygen non-stoichiometry of the perovskite membranes at elevated temperatures.

\section{Plans for the future work:}

1. SEM analysis of the fractured membranes to understand the fracture behavior

2. X-ray diffraction analysis of the calcined and annealed membranes to understand the thermal expansion behavior.

3. Flexural strength studies in the $\mathrm{CO} / \mathrm{CO}_{2}$ on the machined and polished specimens. 
Task. 3: Measurement of Surface Activation/Reaction Rates in Ion Transport Membranes using Isotope Tracer and Transient Kinetic Techniques

\section{A. J. Jacobson, University of Houston, C.A. Mims, University of Toronto}

\section{INTRODUCTION}

Mixed ionic electronic conductors (MIECs) with the $\mathrm{ABO}_{3}$ perovskite or related structures have been widely studied because of their practical applications in iontransport membranes, pressure-driven oxygen generators, partial oxidation reactors, and as electrodes for solid oxide fuel cells (SOFCs) ${ }^{2}$. A number of materials problems remain outstanding for the application of ion transport membrane reactors in the high oxygen partial pressure gradients found, for example, in syn gas generation by partial oxidation of methane. The membrane composition must simultaneously provide the necessary oxygen flux and have stability over a wide $\mathrm{pO}_{2}$ range and appropriate mechanical properties. Our previous findings from isotopic transients show that surface reaction rates on both sides of the membrane are significant kinetic barriers to membrane performance and that the oxidation reactions on the "fuel" side of a syngas membrane can show bistable behavior indicative of a strong coupling between the surface reactivity and the surface composition and oxidation state.

The $\mathrm{La}_{1-x} \mathrm{Sr}_{x} \mathrm{FeO}_{3-\mathrm{x}}$ (LSFO) series has high mixed conductivity and better stability than the $\mathrm{La}_{1-x} \mathrm{Sr}_{x} \mathrm{CoO}_{3-\mathrm{x}}$ (LSCO) series but still exhibits limited stability in low$p \mathrm{O}_{2}$ environments. Additional substitution on the $\mathrm{B}$-site by metal ions that are more difficult to reduce solves some of these problems but issues remain concerning both kinetic and thermodynamic stability and the effects of composition changes that result from partial decomposition or surface segregation on the membrane surface catalytic properties.

In our studies of membrane materials, we have investigated the $\mathrm{pO}_{2}$ and temperature dependence of the conductivity, non-stoichiometry and thermal-expansion behavior of two specific compositions, $\mathrm{La}_{0.2} \mathrm{Sr}_{0.8} \mathrm{Fe}_{0.8} \mathrm{Cr}_{0.2} \mathrm{O}_{3-\mathrm{x}}$ and $\mathrm{La}_{0.2} \mathrm{Sr}_{0.8} \mathrm{Fe}_{0.55} \mathrm{Ti}_{0.45} \mathrm{O}_{3-}$ $x$, by using electrochemical cells and dilatometry ${ }^{[2,3,4,5]}$ Additional measurements on the simpler composition, $\mathrm{La}_{0.5} \mathrm{Sr}_{0.5} \mathrm{FeO}_{3-\mathrm{x}}$ have been made for comparison ${ }^{2}$. These and other 
recent studies of ferrites with the perovskite structure show anomalous behavior at low oxygen partial pressures $\left(<10^{-5}\right.$ atm). Temporary nano-phase segregation behavior involving cation ordering is thought play a role in this bulk behavior. Such behavior is also consistent with the unusual surface reactivity findings. During this reporting period, we have attempted to add more insight to these aspects, particularly the variations in surface structure, composition and reactivity in lanthanum ferrites. Ink-jet printing techniques for solutions of perovskite oxide precursors have been developed to provide complex samples for study by oxygen isotope infusion. This technique will provide variation in composition of the resulting oxide materials and can also be used to synthesize patterned interfaces and modify the composition of existing surfaces. Investigation of oxygen incorporation rates by isotope infusion - SIMS allows a parallel screening of the relationship between composition and reactivity.

The use of composite membranes offers some potential advantages over single phase materials with respect to improved thermal expansion and mechanical properties. The use of metal - ionic conductor composites has been reported by a number of authors. The disadvantage of such systems is that the permeation flux is limited by the surface reaction at the three phase boundary between gas, metal and ionic conductor and consequently is much smaller than predicted by an ambipolar diffusion model ${ }^{2}$. An alternative approach is to combine a mixed electronic ionic conductor with an ionic conductor where the ionic conductor has itself some activity for oxygen reduction. Initial results on the synthesis of dual phase composite materials suggested that gadolinium doped ceria (GDC) is a good choice for the ionic component because it is compatible with high performance mixed conductors. In the previous quarter, procedures for the synthesis of high quality GDC based on a simple precursor for use in composite membranes were reported. We have continued to test the new membrane permeation system and sintering studies of biphasic systems are in progress. The role of the interfaces (e.g. GDC-perovskite) in these membranes is also being investigate by isotope permeation measurements in film samples. 


\section{EXPERIMENTAL}

\section{Ink-jet printed materials for IEDPstudies}

A piezo-electric inkjet printer has been modified to accept flat ceramic substrates. In order to print specified quantities of precursor solutions from the several "ink" containers in the printer, a unique PC printer driver file was assembled. Two oxide precursor "ink" systems were investigated:

(1) The first was a single component solution of cerium nitrate and gadolinium nitrate to prepare CGO patterns.

(2) The second system consisted of two "ink" solutions for preparation of a perovskite oxide of variable composition. The initial target was the composition series $\mathrm{La}_{1-\mathrm{x}} \mathrm{Sr}_{\mathrm{x}}$ $\mathrm{FeO}_{3-\mathrm{y}}$. Thus one solution consisted of a 1:1 stoichiometric mixture of lanthanum nitrate and iron (ferric) nitrate while the second solution consisted of a 1:1 stoichiometric mixture of strontium nitrate and iron (ferric) nitrate.

In order to control the drying and precipitation of materials from the designated solutions, optimized solvent (alcohols, water) and viscosity modifiers (polyethylene oxide) were attempted. A full description of the parameters studied will be included in the next quarterly report. The printed, dried patterns were then calcined to form the mixed oxide materials.

\section{Characterization}

The printed patterned materials are characterized by SEM-EDX and imaging ToFSIMS. Small spot X-ray diffraction is also being pursued to check phase identity and purity.

Oxygen isotope exchange is performed as previously reported. Briefly, this involves (1) pre-conditioning the material at a selected temperature in a flowing stream containing an oxygen exchange medium (molecular oxygen or carbon dioxide based) with natural oxygen isotopic abundances. Following this preconditioning, the flowing gas is switched to a gas stream of similar composition, but enriched in ${ }^{18} \mathrm{O}$. After ${ }^{18} \mathrm{O}$ infusion 
for a finite exchange time, the sample is rapidly removed from the reactor and cooled. The resulting ${ }^{18} \mathrm{O}$ oxygen isotope distribution is then studied by SIMS techniques: (1) by sputter profiling of thin films or shallow profiles (up to 1 micrometer) or (2) by imaging of polished cross sections to study deeper profiles.

\section{Composite membranes}

The previous report discussed the methods developed to produce CGO powders for mixed phase (CGO-perovskite oxide) membranes. Briefly, two different synthesis routes to GDC used either formate or carbonate precursors. The carbonate precursors used the approach of Fujihara et al [i] Following their methods, solutions of $\mathrm{Ce}\left(\mathrm{NO}_{3}\right)_{3} \cdot 6 \mathrm{H}_{2} \mathrm{O}$ and urea were hydrolyzed, forming rod-shaped particles (approximately $5 \times 2 \mu \mathrm{m})$ of $\mathrm{Ce}_{2} \mathrm{O}\left(\mathrm{CO}_{3}\right)_{2} \cdot \mathrm{H}_{2} \mathrm{O}$. When $\mathrm{CeCl}_{3} \cdot 6 \mathrm{H}_{2} \mathrm{O}$ was used instead of nitrate, triangular prism-shaped particles (approximately $20-30 \mu \mathrm{m}$ in height and $5-10 \mu \mathrm{m}$ in thickness) were precipitated. The formate precursor $\mathrm{Ce}(\mathrm{Gd})(\mathrm{HCOO})_{3}$ was synthesized from the nitrates by hydrolysis of dimethylformamide. In typical syntheses $\mathrm{Ce}\left(\mathrm{NO}_{3}\right)_{3} \cdot 6 \mathrm{H}_{2} \mathrm{O}$ and $\mathrm{Gd}\left(\mathrm{NO}_{3}\right)_{3} \cdot 6 \mathrm{H}_{2} \mathrm{O}$ were dissolved in either $\mathrm{DMF} / \mathrm{EtOH} / \mathrm{H}_{2} \mathrm{O}$ or $\mathrm{DMF} / \mathrm{HCOOH} / \mathrm{H}_{2} \mathrm{O}$ and this solution was hydrolyzed to give a high (97\%) yield of needle-shaped white crystals of the formate. The carbonate precursor $(\mathrm{Ce}, \mathrm{Gd})\left(\mathrm{CO}_{3}\right)(\mathrm{OH})$ was prepared via a modification of the precipitation method used by Fujihara et al. with mixed solutions of cerium nitrate and gadolinium nitrate in the ratio of $\mathrm{Ce} / \mathrm{Gd}=9 / 1$ to give a white powder. Finally, the carbonate and formate precursors were heat-treated at $350 \sim 400{ }^{\circ} \mathrm{C}$ for $12 \mathrm{~h}$ to give yellow CGO powders.

Characterization. The precursor and CGO particle morphologies were discussed in the last report, including scanning electron microscopy, thermogravimetric analysis (TGA) and X-ray powder diffraction. Nitrogen adsorption isotherms and conductivity measurements by AC impedance were also peformed. The strength of composite materials through annealing cycles were studied and revealed tendencies to crack. These methods have continued in the present period. 


\section{RESULTS AND DISCUSSION}

\section{Ink-jet printed patterned materials}

Initial patterned materials of the composition $\mathrm{La}_{1-\mathrm{x}} \mathrm{Sr}_{\mathrm{x}} \mathrm{FeO}_{3-\mathrm{y}}$ were printed on (100) oriented single crystal substrates of YSZ. Optimized "ink" solutions for printing of these $\mathrm{La}_{1-\mathrm{x}} \mathrm{Sr}_{\mathrm{x}} \mathrm{FeO}_{3-\mathrm{y}}$ patterns were based on $95 \%$ ethanol and small amounts $(0.1 \%)$ of PEO. A full description of the printing parameters studied will be included in the next quarterly report. Preliminary ToFSIMS images of the printed patterns are shown in Figure 15 below. The general outline of the printed bars are superimposed on the SIMS images. The three thinner horizontal bars in the upper left portion of the images are three compositions with different $\mathrm{Sr} / \mathrm{Fe}$ ratios. The total surface concentrations for these regions were adjusted such that approximately 1 micrometer thick films of perovskite oxide would be formed if the material were dense and evenly distributed. The thicker horizontal bar at the lower left has a higher surface density (equivalent to 10 micrometer average thickness) as does the vertical bar on the right. These preliminary images show a qualitative concurrence with the designed printed pattern. The lower ion yields of $\mathrm{Fe}$ and $\mathrm{LaO}$ ions result in ion counts too small to image in the thin bars. The higher ion yields of $\mathrm{Sr}$ show that the lighter bars were indeed printed. The images also show evidence of uneven "splotchy" application during the printing process, including (1) rows of individual spots in the thinner bars, presumably from individual ink-jet bursts (2) other splotchy appearances, particularly in the strontium map, possibly due to uneven precipitation during drying are evident. Because of the sensitivity variations in SIMS, some of the variability could be topographical, surface orientation or matrix effect derived. Further more detailed analysis of ion ratios and complex ions $(\mathrm{SrFeOx}$ and LaFeOx, e.g.) coupled with SEM and XRD characterization will provide a more complete picture. There is evidence of one smearing event in the strontium map, but otherwise the pattern shows a successful control of the printing procedure. 

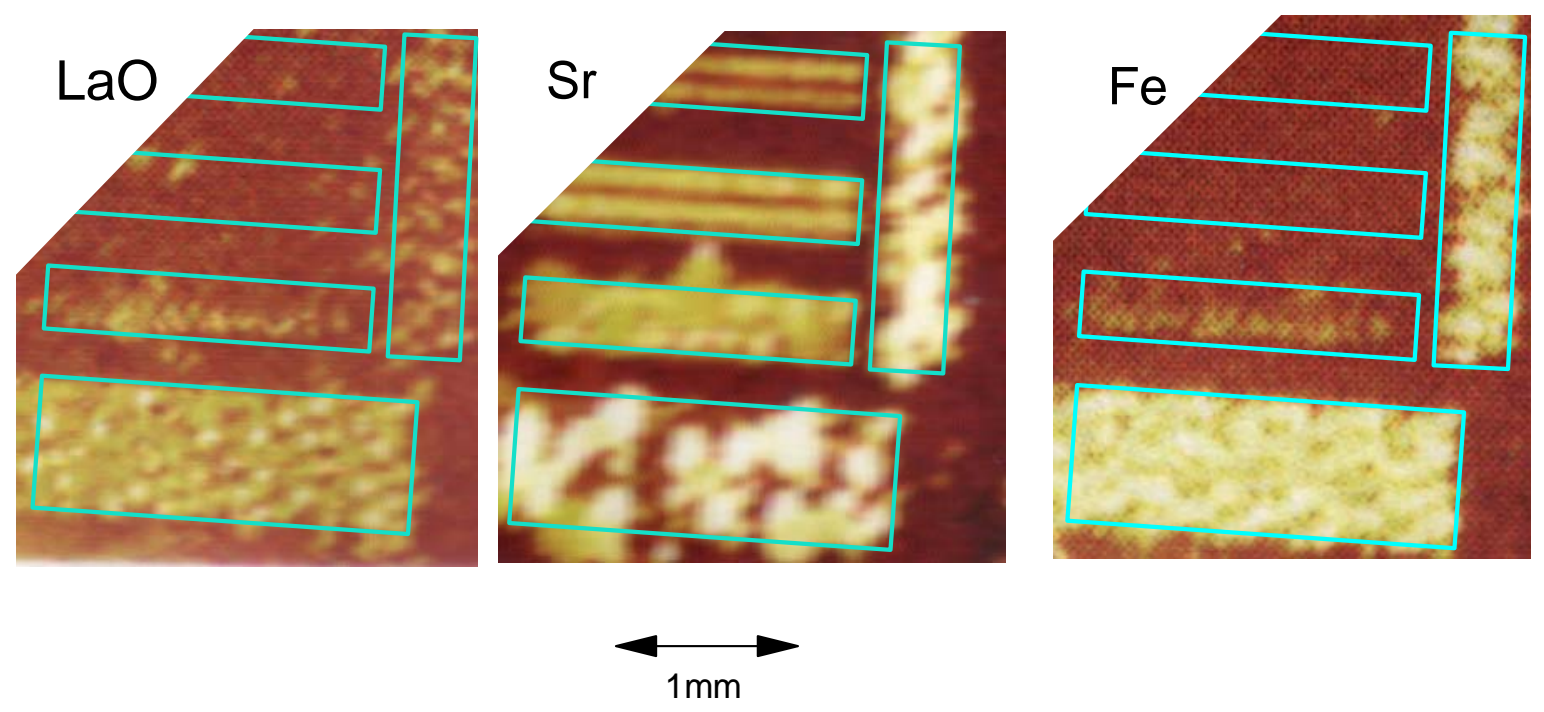

Figure 15: ToFSIMS images (positive ions) of printed, dried and calcined patterns of $\mathrm{La}_{1}$ ${ }_{x} \mathrm{Sr}_{\mathrm{x}} \mathrm{FeO}_{3-\mathrm{y}}$ on $\mathrm{YSZ}(100)$.

This sample was exposed to ${ }^{18} \mathrm{O}_{2}$ (20\% in Ar with $90 \%{ }^{18} \mathrm{O}$ isotopic abundance) for 5 minutes at $400^{\circ} \mathrm{C}$. The resulting ${ }^{18} \mathrm{O}$ ToFSIMS map (negative ion) is shown below in Figure 16. The Sr map from Figure 15 is also included.

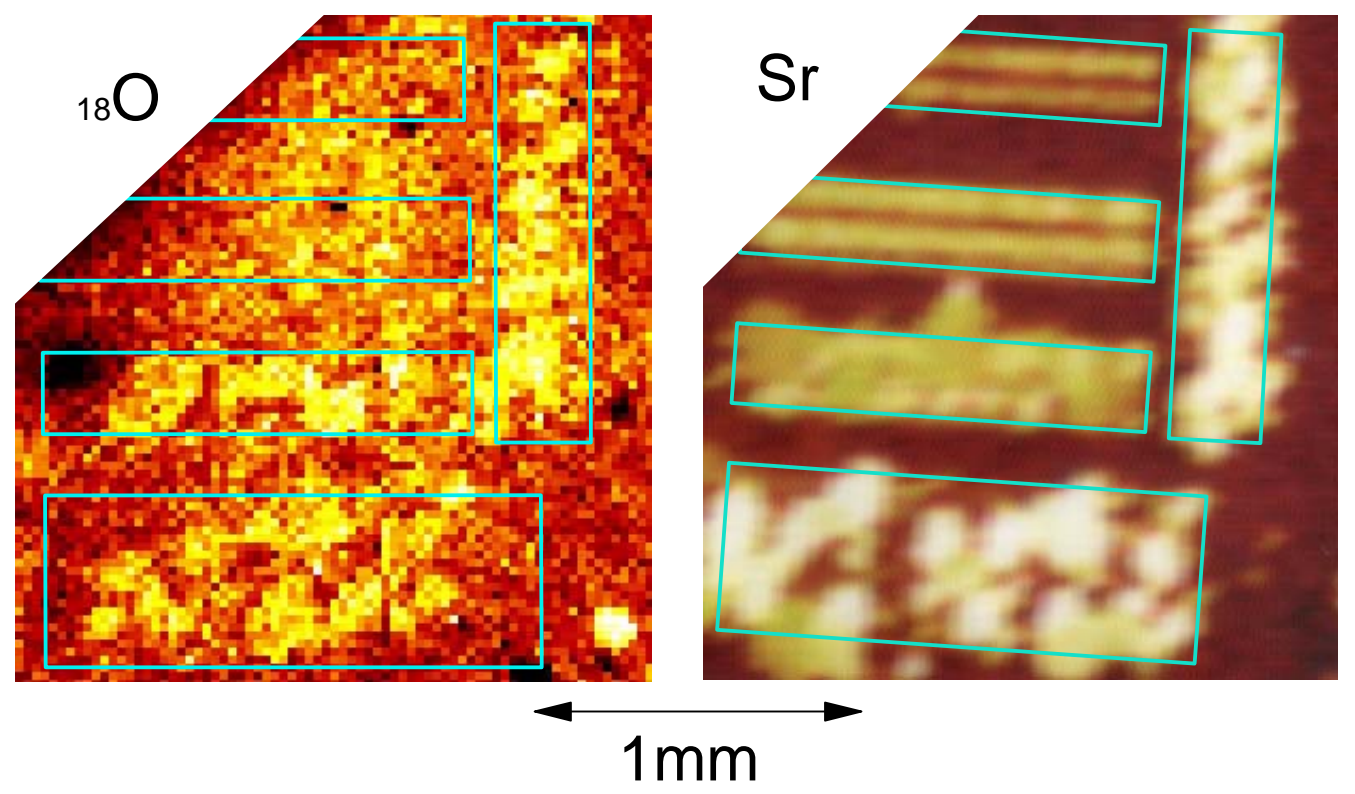

Figure 16: ${ }^{18} \mathrm{O}$ ToFSIMS image of infused patterned sample of $\mathrm{La}_{1-\mathrm{x}} \mathrm{Sr}_{\mathrm{x}} \mathrm{FeO}_{3-\mathrm{y}}$ on $\mathrm{YSZ}$ (100). 
The pixel resolution in the ${ }^{18} \mathrm{O}$ map is lower than in the positive ion images in Figure 15. Nevertheless, a correspondence between the cation images and the ${ }^{18} \mathrm{O}$ image can be seen, including a rough correspondence between the "splotches" in the Sr image and some of the "hot spots" in the ${ }^{18} \mathrm{O}$ image. Again, analysis of ion ratios will provide more quantitative characterization of the results. There is also evidence in Figure 16 of ${ }^{18} \mathrm{O}$ incorporated at regions between the bars, particularly the bright spot in the lower right - due to an unidentified contaminant. The ToFSIMS data can and will analyzed to look for a cation contaminant associated with this spots and other inter-bar regions of ${ }^{18} \mathrm{O}$ incorporation. There does not appear to be a "triple phase boundary" effect on ${ }^{18} \mathrm{O}$ activation with a "hot boundary" of ${ }^{18} \mathrm{O}$ activation. Given the apparent uneven nature of the material, this is not surprising. ${ }^{18} \mathrm{O}$ is also incorporated directly onto $\mathrm{YSZ}$ and has been studied by this group before. More quantitative analysis of all these preliminary data will be pursued in the ensuing reporting period. Nevertheless, the utility of this procedure for screen of new materials and the spatial dependence of oxygen incorporation should be apparent from these cursory, preliminary results.

\section{Composite membranes:}

Attempts to synthesize optimized powders for composite membranes and the production of composite materials has continued. The issues identified in the previous reporting and our current activities are summarized briefly here.

(1) The large crystal sizes of the formate precursor result in powders that do not densify easily. Attempts to influence this with surfactants, heat treatment variations and rapid quenching were not unsuccessful. No solution to this problem has been found during the current period, although rapid quenching of the oxide produces somewhat smaller oxide particles than that of the formate precursor.

(2) Smaller crystal sizes (approximately 1 micrometer), and also smaller yields, from carbonate precursors were achieved by variations of the synthesis temperature and urea/solute ratios. At the reaction temperature over $100^{\circ} \mathrm{C}$, the ratio of 1:3 gave a 
maximum yield of $99.9 \%$. The resulting carbonate crystals were small square blocks with dimensions of 1 x 1 x $0.5 \mu \mathrm{m}$ (Fig. 16b).

(3) The resulting powders have substantial internal surface area.

(4) AC impedance results are similar to the best in previous literature reports and show contribution of both grain boundary and bulk contributions. These studies have continued and initial attempts to synthesize composites from these CGO powders have been performed. Cracking is still causing problems and will be reported in more detail in the next report.

\section{Plans for the Next Quarter.}

The ink-jet printing studies will be extended, both in characterization and in the analysis of the oxygen activation characteristics. Attempts to print CGO and perovskite oxides on a single sample will also be scheduled. In the next quarter we will continue densification studies of both $\mathrm{La}_{2} \mathrm{NiO}_{4}$ and $\mathrm{PrBaCo}_{2} \mathrm{O}_{5}$ composites with CGO. The initial compositions will use 25 and $50 \%$ CGO to cover the range above and below the CGO percolation threshold. We will measure the thermal expansion coefficients of the composite materials. Assuming that dense samples can be prepared, we will then carry out permeation measurements. IDEP measurements on a composite material will be performed, when available, to reveal the contribution of the individual phases and interphase regions to oxygen permeation. A new apparatus for this purpose has been constructed and tested during the last quarter. 


\section{CONCLUSIONS}

The total electrical conductivity and Seebeck coefficient were measured in air on both porous $(50 \%)$ and dense (>90\%) LSFT samples, which were prepared using nanocrystalline powders. The conductivity in air at $900^{\circ} \mathrm{C}$ was about 0.19 and $1.5 \mathrm{~S} / \mathrm{cm}$ for porous and dense LSFT, respectively. The activation energy of conduction for the porous and dense LSFT was about $0.2 \mathrm{eV}$ and $0.20-0.33 \mathrm{eV}$, respectively. The average value of the acceptor dopant concentration based on Seebeck and electrical conductivity measurements on the porous LSFT was calculated to be 0.35 , which suggests that the dopants were fully ionized at the lowest temperature, $400^{\circ} \mathrm{C}$.

Thermal analysis of the fractured dual phase membranes at $1000^{\circ} \mathrm{C}$ in air and $\mathrm{N}_{2}$ and $\mathrm{CO} / \mathrm{CO}_{2}$ atmosphere has been carried out and the results were compared with that of the as received dual phase membranes carried out in air and $\mathrm{N}_{2}$. The dual phase samples were calcined at 1000 and $1250^{\circ} \mathrm{C}$ in air and annealed at $1000^{\circ} \mathrm{C}$ in air and $\mathrm{N}_{2}$ for TGA. The results confirmed the non-stoichiometry of the membranes at the elevated temperatures. Thermal expansion of the LSFT and dual phase membranes were characterized using dilatometer in air and $\mathrm{N}_{2}$.

We have incorporated a new screening and model material synthesis technique (ink jet printing) to membrane studies. We continue to make progress on simple inexpensive precursor route to $\mathrm{CGO}$ for high quality composite material that can be easily densified. Further studies of the use of this material in composite membranes are in progress. 


\section{LIST OF ACRONYMS AND ABBREVIATIONS}

CGO

Cerium gadolinium oxide

GDC

Gadolinia doped ceria

IEDP

Isotope exchange -depth profiling

PEG,PEO

Polyethylene glycol, polyethylene oxide

SEM-EDX

Scanning Electron Microscopy-Energy Dispersed X-ray analysis

ToFSIMS

Time of Flight Secondary Ion Mass Spectroscopy

YSZ

Yttria stabilized Zirconia

XRD

X-ray diffraction 


\section{REFERENCES}

\section{UMR}

1. D.P. Fagg et al., Solid State Ionics, 156 (2003) 45-57

\section{UH}

2

H. J. M. Bouwmeester, A. J. Burggraaf, "The CRC Handbook of Solid State Electrochemistry", Eds. P. J. Gellings and H. J. M. Bouwmeester, CRC Press, Boca Raton, (1997) 481.

3

Yoo, A. Verma, and A. J. Jacobson, Proc. Electrochem. Soc. PV2001-28 (2002)

4

J. Yoo, A. Verma, S. Wang, and A. J. Jacobson, J. Electrochem. Soc. 152 (2005) A497.

5

C. Y. Park and A. J. Jacobson, J. Electrochem. Soc. 152 (2005) J65.

6

C. Y. Park and A. J. Jacobson, Solid State Ionics 176/35-36 (2005) 2671.

7

8

J. Yoo, C. Y. Park and A. J. Jacobson, Solid State Ionics 175(1-4) (2004) 55.

T. H. Lee, Y. L. Yang, A. J. Jacobson, Solid State Ionics, 134 (2000), 331 and references therein.

$9 \quad$ M. Oikawa, S. Fujihara, J. Solid State Chem. 178 (2005) 2036. 